\title{
Chemical, immunobiological and antigenic characterizations of lipopolysaccharides from Bacteroides gingivalis strains
}

\author{
Taku Fujiwara, ${ }^{1,2}$ Tomohiko Ogawa, ${ }^{1}$ Shizuo Sobue ${ }^{2}$ and Shigeyuki Hamada ${ }^{1 *}$ \\ Departments of Oral Microbiology ${ }^{1}$ and Pedodontics ${ }^{2}$, Osaka University Faculty of Dentistry, 1-8 Yamadaoka, \\ Suita-Osaka 565, Japan
}

(Received 6 September 1989; revised 27 October 1989; accepted 13 November 1989)

\begin{abstract}
Lipopolysaccharides (LPS) were extracted from whole cells of seven strains of Bacteroides gingivalis - 381, ATCC 33277, BH18/10, OMZ314, OMZ409, 6/26 and HW24D-1 - by the phenol/water procedure, and purified by treatment with nuclease and by repeated ultracentrifugation. These LPS were composed of hexoses, hexosamines, fatty acids, phosphorus and phosphorylated 2-keto-3-deoxyoctonate (KDO). The major components of the lipid portion of these LPS were hexadecanoic, 3-hydroxyhexadecanoic, branched 3-hydroxypentadecanoic and branched 3-hydroxyheptadecanoic acids. All the LPS preparations induced marked mitogenic and in vitro polyclonal B cell activation responses in spleen cells from both $\mathrm{C} 3 \mathrm{H} / \mathrm{HeN}$ and $\mathrm{C} 3 \mathrm{H} / \mathrm{HeJ}$ mice, exhibited no definitive preparatory activity in the local Shwartzman reaction in rabbits, but were active in the chromogenic Limulus amoebocyte lysate test. A monoclonal antibody $(\mathrm{mAb})$ raised against the LPS from $B$. gingivalis strain 6/26 reacted with LPS from all other $B$. gingivalis strains tested. Other $m A$ bs raised against LPS from $B$. gingivalis strains 381 and 6/26 reacted with the LPS from strains 381, ATCC 33277, BH18/10 and 6/26 (these strains were termed LPS serogroup I), as revealed by ELISA and immunodiffusion. The LPS from these strains except for 6/26 showed almost indentical patterns in SDS-PAGE stained with ammoniacal silver. A mAb raised against the LPS from $B$. gingivalis HW24D-1 reacted with the LPS from strains OMZ314, HW24D-1 and OMZ409 (LPS serogroup II). These LPS, except OMZ409, exhibited very similar profiles in SDS-PAGE. These results indicate that there are at least two different antigenic groups present among LPS from $B$. gingivalis strains, as well as a common, species-specific antigen.
\end{abstract}

\section{Introduction}

Bacteroides gingivalis is a Gram-negative, anaerobic, black-pigment-forming, rod-shaped bacterium, and is suspected of being a major pathogenic organism in adult periodontitis. It has a variety of cellular and extracellular components which may modify host responses leading to the destruction of periodontal tissues (Slots \& Genco, 1984; Mayrand \& Holt, 1988; Slots \& Listgarten, 1988). Among them, one of the most important is endotoxic lipopolysaccharides (LPS). LPS are a major component in the outer membrane of Gram-negative bacteria, and possess marked immunobiological and pharmacological activities (Daly et al., 1980; Morrison, 1983; Westphal et al., 1985). As compared with the 'classical' LPS from Enterobacteriaceae, LPS from Bacteroides species have

Abbreviations: Con A, concanavalin A; CI, chemical ionization; EI, electron impact ionization; KDO, 2-keto-3-deoxyoctonate (3-deoxy-Dmanno-2-octulosonate); LAL test, Limulus amoebocyte lysate test; LPS, lipopolysaccharide(s); mAb, monoclonal antibody. some different properties in terms of chemical composition and immunobiological activities. Chemically, heptose and 2-keto-3-deoxyoctonate (KDO), which are components of the core region of classical LPS, and 3hydroxymyristic acid, a main fatty acid of endotoxic lipid A, are not detectable by the usual methods. Immunobiologically, the LPS induce activation of lymphoid cells from the classical LPS nonresponder mouse strain C3H/HeJ (Hamada et al., 1988).

LPS are located on the cell surface; their polysaccharide portion is oriented toward the outside originating from within the outer membrane, and some immunodeterminant sugar residues may be easily recognized by immunocompetent cells. Thus, LPS can be highly antigenic. Schenck \& Michaelsen (1987) reported that patients with periodontitis exhibited significantly higher levels of serum antibody specific for $B$. gingivalis LPS when compared to subjects with a healthy periodontium. Furthermore, periodontal treatment reduced the level of the serum antibody against $B$. gingivalis LPS (Schenck $e t$ 
$a l ., 1987)$. These findings clearly suggest that $B$. gingivalis LPS play an important role not only as an immunomodulator but also as an antigen in the pathogenesis of periodontal diseases.

Because investigators have long focused mainly on two reference strains of $B$. gingivalis, strains 381 and ATCC 33277, the inter-strain differences among $B$. gingivalis LPS have not yet been characterized. We report here the determination of the chemical, immunobiological and antigenic properties of LPS from seven strains of $\boldsymbol{B}$. gingivalis.

\section{Methods}

Bacterial strains and preparation of LPS. Bacteroides gingivalis strains 381, ATCC 33277, BH18/10, OMZ314, OMZ409, 6/26 and HW24D-1 were used in this investigation. In some experiments, Escherichia coli K235 grown in Trypticase soy broth (BBL) was used as a source of control LPS. B. gingivalis strains were cultured anaerobically in GAM broth (Nissui, Tokyo) supplemented with haemin and menadione at $37^{\circ} \mathrm{C}$. Bacterial cells were collected by centrifugation, washed twice with pyrogen-free water and lyophilized. LPS were extracted from lyophilized cells by the hot phenol/water method described by Westphal \& Jann (1965). The crude extract was suspended in pyrogenfree water and collected by ultracentrifugation $(100000 \mathrm{~g}, 3 \mathrm{~h})$, followed by treatment with nuclease P1 (Yamasa Shoyu Co.). Subsequently, crude LPS extracts were purified by repeated ultracentrifugation and finally lyophilized. In some experiments, LPS from oral blackpigmented and related Bacteroides strains such as $B$. oralis ATCC $33269, B$. loescheii ATCC 15930, B. intermedius ATCC 25611 and $B$. corporis ATCC 33547 were used (Fujiwara et al., 1988).

Colorimetric analysis. Total hexose was estimated by the anthrone method (Trevelyan \& Harrison, 1956) with glucose as a standard. Protein was measured by using the BCA protein assay reagent (Pierce Chemical Co.) with BSA (Sigma) as a standard. Total fatty acid esters, heptose, KDO and phosphorus were quantified by colorimetric methods as previously described (Koga et al., 1985). Phosphorylated KDO was quantified as follows (Kumada $e t$ al., 1988). LPS from $B$. gingivalis were hydrolysed in $3 \mathrm{M}-\mathrm{HCl}$ at $100{ }^{\circ} \mathrm{C}$ for $30 \mathrm{~min}$. The hydrolysates were dried in vacuo, suspended in $0 \cdot 1 \mathrm{M}-\mathrm{H}_{2} \mathrm{SO}_{4}$, and assayed by the thiobarbituric acid method (Karkhanis et al., 1978) with KDO (Sigma) as a standard.

$G L C$. For analysis of component sugars and fatty acids, LPS was hydrolysed for $6 \mathrm{~h}$ at $100^{\circ} \mathrm{C}$ in $2 \mathrm{M}-\mathrm{HCl}$, and the hydrolysate separated by the chloroform/methanol method (Bligh \& Dyer, 1959). Neutral and amino sugars were identified as alditol acetate derivatives (Sawardeker et al., 1965) by using a gas-liquid chromatograph (model GC-15A: Shimadzu) fitted with a glass column $(3 \mathrm{~mm} \times 2 \mathrm{~m})$ of Silicone OV-225 on Chromosorb WAW DMCS (80/100 mesh; Gasukuro Kogyo, Tokyo). Fatty acids were identified as their methyl esters. The chloroform extract was treated with $4 \mathrm{ml} 5 \%(\mathrm{w} / \mathrm{v}) \mathrm{HCl}$ in methanol at $105^{\circ} \mathrm{C}$ for $3 \mathrm{~h}$ in sealed tubes and dried under a stream of nitrogen gas. After the addition of $2 \%(w / v)$ potassium bicarbonate solution, the esters were extracted into hexane and quantified in a gas-liquid chromatograph fitted with an SPB-1 capillary column $(0.25 \mathrm{~mm} \times 30$ $\mathrm{m}$; Supelco). The component fatty acids of LPS were determined by comparison of their retention time with those of known fatty acids. Bacterial acid methyl esters CP mix (Supelco) was used as references for fatty acids.
Mass spectrometry. A model M-2000 mass spectrometer (Hitachi) and a model G-3000 gas-liquid chromatograph (Hitachi) with SPB-1 capillary column were used. Helium was the carrier gas. Electron impact ionization (EI) spectra were recorded using an ionizing energy of $70 \mathrm{eV}$ and an ion-source temperature of $200^{\circ} \mathrm{C}$. Chemical ionization (CI) mass spectra were recorded with isobutane as a reactant gas and with an ion-source temperature of $140{ }^{\circ} \mathrm{C}$.

$S D S-P A G E$. This was done with $4 \%(\mathrm{w} / \mathrm{v})$ stacking and $12.5 \%(\mathrm{w} / \mathrm{v})$ resolving gels as described previously (Fujiwara et al., 1988). After electrophoresis, the gels were stained with ammoniacal silver by the method of Tsai \& Frasch (1982) or with Coomassie brilliant blue.

Assay for mitogenic response and polyclonal $B$ cell activation. $\mathrm{C} 3 \mathrm{H} / \mathrm{HeN}$ and $\mathrm{C} 3 \mathrm{H} / \mathrm{HeJ}$ mice were purchased from CLEA Japan. Spleen cells were obtained from mice aged 6-12 weeks. Mitogenic response and polyclonal $B$ cell activation assays of $\mathrm{C} 3 \mathrm{H} / \mathrm{HeN}$ and $\mathrm{C} 3 \mathrm{H} / \mathrm{HeJ}$ mice spleen cells to LPS from $B$. gingivalis were done as described previously (Fujiwara et al., 1988). Briefly, spleen cell suspensions were cultured with stimulants in RPMI 1640 medium (Gibco) with HEPES buffer $(15 \mathrm{mM}, \mathrm{pH} 7.2)$ at $37^{\circ} \mathrm{C}$ for $48 \mathrm{~h}$ in a humidified atmosphere of $\operatorname{air} / \mathrm{CO}_{2}(95: 5, \mathrm{v} / \mathrm{v})$. The cultures were pulsed for the last $6 \mathrm{~h}$ with $0.25 \mu \mathrm{Ci}(9.25 \mathrm{kBq})\left[{ }^{3} \mathrm{H}\right]$ thymidine (Amersham). Incorporated $\left[{ }^{3} \mathrm{H}\right]$ thymidine was counted in an LKB scintillation counter (model 1215). Concanavalin A (Con A; Sigma) and LPS from $E$. coli $\mathrm{K} 235$ were used as reference mitogens.

For the polyclonal B cell activation assay, lymphoid cells were prepared from the spleens of $\mathrm{C} 3 \mathrm{H} / \mathrm{HeN}$ and $\mathrm{C} 3 \mathrm{H} / \mathrm{HeJ}$ mice by using Histopaque 1085 (Sigma). The lymphoid cells were cultured in RPMI 1640 medium supplemented with $10 \%(\mathrm{v} / \mathrm{v})$ foetal calf serum and 2-mercaptoethanol $(50 \mu \mathrm{M})$ for $96 \mathrm{~h}$. An anti-sheep red blood cell haemolytic plaque assay was then done, as described by Cunningham \& Szenberg (1968).

Limulus amoebocyte lysate ( $L A L)$ assay. A chromogenic LAL assay kit QCL-1000 (Whittaker M. A. Bioproducts) was used. LPS (1 pg dissolved in $50 \mu \mathrm{l}$ of pyrogen-free water) was reacted with the same volume of LAL solution. The reaction mixture was incubated in flatbottomed 96-well microtitre plates (Corning) at $37^{\circ} \mathrm{C}$ for $10 \mathrm{~min}$. Chromogenic substrate $(100 \mu \mathrm{l})$ was added and reacted for $3 \mathrm{~min}$. After stopping the reaction by adding $100 \mu 125 \%(\mathrm{v} / \mathrm{v})$ acetic acid, the absorbance at $405 \mathrm{~nm}$ was measured in a Titertek Multiscan photometer. The standard LPS from E. coli O111: B4 supplied with the assay kit was included for comparison.

Local Shwartzman reaction. This was assessed by using the dorsum of rabbits (about $3 \mathrm{~kg}$ body weight) as described previously (Koga et al., 1987). The LPS from $B$. gingivalis and $E$. coli were suspended in pyrogen-free saline $(0.85 \% \mathrm{NaCl})$ to a concentration of $1 \mathrm{mg} \mathrm{ml}^{-1}$, and twofold serial dilutions were made in pyrogen-free saline and injected intradermally $(200 \mu \mathrm{l})$ into the dorsum. After $24 \mathrm{~h}, E$. coli K235 LPS $(200 \mu \mathrm{g})$ was injected intravenously as a provocation dose. The diameter of the necrotic zone and the redness of the lesion were measured $24 \mathrm{~h}$ after the provocation.

Immunological procedures. Immunodiffusion tests were done in $1 \%$ (w/v) Noble agar (Difco). Antisera against LPS from B. gingivalis were obtained from rabbits as described previously (Fujiwara et al., 1988) and the IgG fraction was prepared by three repeated precipitations with $33 \%$ saturation ammonium sulphate. ELISA was done as follows. LPS dissolved in 0.05 $\mathrm{M}$-sodium carbonate buffer ( $\mathrm{pH} \mathrm{9.6)} \mathrm{was} \mathrm{added} \mathrm{to}$ wells $(1 \mu \mathrm{g}$ per well) of flat-bottomed microtitre plates (MS-3696F ; Sumitomo Bakelite Co., Tokyo). Following overnight incubation at $4{ }^{\circ} \mathrm{C}$, unbound LPS was washed off with $0.01 \mathrm{M}$-potassium phosphate buffer (pH 7.4) containing $0.8 \% \mathrm{NaCl}, 0.02 \% \mathrm{KCl}, 0.01 \% \mathrm{NaN}_{3}$ and $0.05 \%(\mathrm{v} / \mathrm{v})$ Tween 20 (PBST). PBST was used in all washing procedures and as a diluent buffer. Then, $100 \mu 11 \%(\mathrm{w} / \mathrm{v})$ BSA in PBST 
was added, and the plates were incubated at $25^{\circ} \mathrm{C}$ for $1 \mathrm{~h}$. The plate was washed twice and diluted (200-1000-fold) rabbit anti-LPS serum or undiluted hybridoma culture supernatant was added ( $100 \mu \mathrm{l}$ per well). Following incubation at $37^{\circ} \mathrm{C}$ for $1 \mathrm{~h}$, the plates were washed a further three times and then diluted (1000-fold) alkaline-phosphatase-conjugated swine anti-rabbit immunoglobulins (Dakopatts) and alkalinephosphatase-conjugated goat anti-mouse Ig mixture of IgG/IgA/IgM (Zymed Laboratories) were added (100 $\mu \mathrm{l}$ per well). The plates were incubated at $37^{\circ} \mathrm{C}$ for $1 \mathrm{~h}$, washed five times, and p-nitrophenyl phosphate substrate (Wako; Osaka) dissolved in diethanolamine buffer ( $\mathrm{pH} 9.8 ; 1 \mathrm{mg} \mathrm{ml}^{-1}$ ) was added (100 $\mu \mathrm{g}$ per well). The amount of colour developed after incubation at $37^{\circ} \mathrm{C}$ for $1 \mathrm{~h}$ was measured at $405 \mathrm{~nm}$ by using a Titertek Multiscan photometer.

$m A b$ production. LPS $(0 \cdot 1 \mathrm{mg})$ from $B$. gingivalis strains $381,6 / 26$ or HW24D-1 were suspended in $0 \cdot 1 \mathrm{ml}$ of pyrogen-free saline, mixed with an equal volume of Freund's complete adjuvant (Difco), and injected intradermally into the dorsum of BALB/c mice (CLEA Japan). This injection was repeated three times at 2 -week intervals. Four days after the last immunization, spleen cells were fused to myeloma cell line Sp2/O-Ag14 with $50 \%(w / v)$ polyethylene glycol 4000 . After selection of hybrid cells with HAT medium (Boehringer), the presence of antiLPS antibodies in culture fluids was determined by ELISA as described above. The antibody-forming cultures were cloned at least twice by the limiting dilution method. The isotype and light chain of each $\mathrm{mAb}$ was determined by using the mouse monoclonal antibody isotyping kit (Amersham). Culture supernatants of the antibody-producing hybridomas were concentrated about 30 times by ultrafiltration using a Centriprep-30 (Amicon), and were used for reaction with LPS by immunodiffusion.

\section{Results}

\section{Chemical composition of LPS from B. gingivalis}

The yield of purified LPS from lyophilized whole cells of $B$. gingivalis was $0 \cdot 13-0 \cdot 78 \%(\mathrm{w} / \mathrm{w})$. The purified preparations of LPS were composed of rhamnose, hexoses (mannose, galactose and glucose in the order of weight percentage described), hexosamines, fatty acids and phosphorus (Table 1). The total amount of hexose as determined by the anthrone method was $21 \cdot 1-66 \cdot 4 \%$ $(w / w)$. Significant amounts of KDO were not detected when LPS from $B$. gingivalis were hydrolysed in $0.1 \mathrm{M}-$ $\mathrm{H}_{2} \mathrm{SO}_{4}$ at $100^{\circ} \mathrm{C}$ for $30 \mathrm{~min}$, but hydrolysis in $3 \mathrm{M}-\mathrm{HCl}$ released $0.6-1 \cdot 1 \%(\mathrm{w} / \mathrm{w})$ of phosphorylated KDO.

In addition to rhamnose and hexoses, glucosamine, galactosamine and an unknown sugar were detected by GLC. The LPS from B. gingivalis strains ATCC 33277, BH18/10, OMZ409, and 6/26 contained larger amounts of glucose than other $B$. gingivalis strains tested. The BCA protein assay indicated that LPS contained 2.6$6.3 \%(w / w)$ protein. However, no visible protein bands were detected by staining of SDS-PAGE slabs with Coomassie blue after electrophoresis (results not shown) of these LPS preparations $(100 \mu \mathrm{g})$. Very low levels of heptose $(<0.5 \%)$ were detected by the colorimetric method.

Analysis by GLC and GLC-MS revealed that the major fatty acids of LPS from $B$. gingivalis were hexadecanoic (C16:0), 3-hydroxyhexadecanoic (3-OHC16:0), branched 3-hydroxypentadecanoic (branched 3$\mathrm{OH}-\mathrm{C15:0)}$ and branched 3-hydroxyheptadecanoic (branched 3-OH-C17:0) (Table 2). In contrast to straight forms of 3-hydroxy fatty acid methyl esters, the branched 3-hydroxy fatty acid methyl esters gave the same base peak $(m / e 108)$ and characteristic ions such as $M^{+}-50$ and $M^{+}-18$ by the EI-MS. They also showed the same molecular mass by CI-MS with isobutane. However, their retention times were different from the straight forms of 3-hydroxy fatty acids in GLC. These branched fatty acids were characteristic of LPS preparations from B. gingivalis. Some iso-branched fatty acids such as 13methyltetradecanoic (iso-C15:0), and 15-methylhexadecanoic (iso-C17:0) were also detected in B. gingivalis LPS preparations.

Table 1. Chemical composition of LPS from B. gingivalis

Data are expressed as the mean \pm SD of at least triplicate assays. ND, Not detected.

\begin{tabular}{|c|c|c|c|c|c|c|c|}
\hline \multirow[b]{2}{*}{ Component: } & \multicolumn{7}{|c|}{ Percentage $(w / w)$ dry weight } \\
\hline & 381 & ATCC 33277 & $\mathrm{BH} 18 / 10$ & $6 / 26$ & OMZ314 & HW24D-1 & OMZ409 \\
\hline Total hexose $\mathrm{e}^{a}$ & $25.4 \pm 1.7$ & $49.4 \pm 1.8$ & $46 \cdot 1 \pm 2 \cdot 2$ & $43 \cdot 3 \pm 1 \cdot 0$ & $21 \cdot 1 \pm 0 \cdot 6$ & $24.4 \pm 1.6$ & $66 \cdot 4 \pm 1 \cdot 1$ \\
\hline Rhamnose $^{b}$ & $3.8 \pm 0.3$ & $2.0 \pm 0.2$ & $1.8 \pm 0.2$ & $1.4 \pm 0.1$ & $2 \cdot 5 \pm 0 \cdot 2$ & $2 \cdot 3 \pm 0.2$ & $0.5 \pm 0.1$ \\
\hline Mannose $^{b}$ & $3 \cdot 3 \pm 0.3$ & $2 \cdot 1 \pm 0.2$ & $1.7 \pm 0.2$ & $1.3 \pm 0.2$ & $2 \cdot 6 \pm 0 \cdot 3$ & $2.6 \pm 0.4$ & $0.5 \pm 0.1$ \\
\hline Galactose $^{b}$ & $7 \cdot 1 \pm 0.5$ & $4.9 \pm 0.8$ & $3 \cdot 3 \pm 0 \cdot 1$ & $2.5 \pm 0.2$ & $4 \cdot 0 \pm 0 \cdot 3$ & $3.2 \pm 0.3$ & $0.7 \pm 0.1$ \\
\hline Glucose $^{b}$ & $5.3 \pm 1 \cdot 2$ & $28.4 \pm 1.3$ & $14.4 \pm 0.4$ & $20.4 \pm 3.8$ & $3.5 \pm 0.7$ & $5.6 \pm 1.0$ & $28 \cdot 7 \pm 0 \cdot 1$ \\
\hline Unknown ${ }^{b} \dagger$ & $0.3 \pm 0.0$ & ND & $0.7 \pm 0 \cdot 1$ & $2 \cdot 1 \pm 0.4$ & $1 \cdot 2 \pm 0 \cdot 2$ & $0 \cdot 3 \pm 0 \cdot 1$ & $1 \cdot 7 \pm 0 \cdot 3$ \\
\hline Glucosamine $^{b}$ & $11.3 \pm 0.9$ & $8.3 \pm 0.7$ & $9.8 \pm 0.3$ & $6.2 \pm 0.7$ & $13.3 \pm 1.4$ & $11 \cdot 3 \pm 1 \cdot 2$ & $3 \cdot 6 \pm 0.4$ \\
\hline Galactosamine $^{b}$ & $6.2 \pm 0.2$ & $2 \cdot 2 \pm 0 \cdot 1$ & $2 \cdot 6 \pm 0.1$ & $4 \cdot 8 \pm 0 \cdot 1$ & $4.9 \pm 0.1$ & $4.6 \pm 0.0$ & $1.5 \pm 0.0$ \\
\hline Phosphorylated $\mathrm{KDO}^{a}$ & $1 \cdot 0 \pm 0 \cdot 1$ & $0.6 \pm 0.0$ & $0.7 \pm 0.1$ & $0 \cdot 9 \pm 0 \cdot 1$ & $1.1 \pm 0.2$ & $1.0 \pm 0.1$ & $0 \cdot 6 \pm 0 \cdot 1$ \\
\hline Total lipid ${ }^{a}$ & $23 \cdot 3 \pm 0.2$ & $13.4 \pm 0.1$ & $8.7 \pm 1.9$ & $17.6 \pm 1.4$ & $14 \cdot 0 \pm 1 \cdot 1$ & $22.6 \pm 2.9$ & $6 \cdot 8 \pm 1 \cdot 1$ \\
\hline Phosphorus $^{a}$ & $2 \cdot 8 \pm 0 \cdot 0$ & $1.7 \pm 0.0$ & $1.9 \pm 0.0$ & $2 \cdot 3 \pm 0 \cdot 1$ & $3.0 \pm 0.0$ & $3 \cdot 2 \pm 0 \cdot 2$ & $0.5 \pm 0.0$ \\
\hline Protein $^{a}$ & $3 \cdot 1 \pm 1 \cdot 1$ & $6 \cdot 3 \pm 1 \cdot 1$ & $3.4 \pm 0.0$ & $3.3 \pm 0.7$ & $3 \cdot 1 \pm 0 \cdot 0$ & $2.6 \pm 0.2$ & $6.3 \pm 0.5$ \\
\hline
\end{tabular}

* $a$, Quantified by colorimetric analysis; $b$, quantified by GLC.

† Calculated by assuming that the response adjustment factor of the unknown sugar was the same as that of glucose with GLC. 
Table 2. Fatty acid composition of LPS from B. gingivalis

Fatty acid composition was determined by GLC and GLC-MS. Data are expressed as the mean \pm SD of at least triplicate assays. ND, Not detected; tr., trace amount $(<1 \%)$.

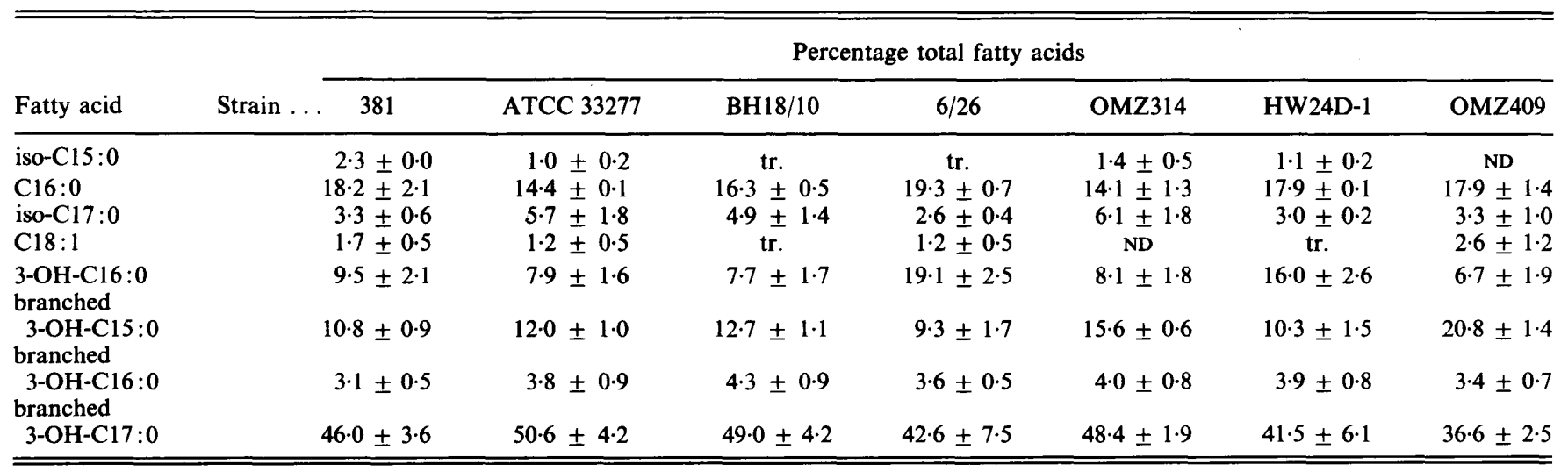

\section{SDS-PAGE of LPS from B. gingivalis}

Silver-stained profiles of the LPS preparations from the seven strains of $\boldsymbol{B}$. gingivalis are shown in Fig. 1. Each showed a series of closely spaced bands in a ladder pattern. The LPS profiles of strains 381, ATCC 33277 and $\mathrm{BH} 18 / 10$, and of strains OMZ314 and HW24D-1 were almost identical, within each cluster of strains. Although the profiles of $6 / 26$ and OMZ409 were different from the two clusters mentioned above, they showed some similarity to those of strain 381 and strain OMZ314, respectively.

\section{Immunobiological activities of LPS from B. gingivalis}

LPS preparations from all the $B$. gingivalis strains induced strong mitogenic responses and in vitro polyclonal B cell activation responses in cultures of spleen cells from both LPS-nonresponder $\mathrm{C} 3 \mathrm{H} / \mathrm{HeJ}$ mice (Fig. 2) and LPS-responder $\mathrm{C} 3 \mathrm{H} / \mathrm{HeN}$ mice (results not shown). The response patterns of spleen cells from these mice were essentially identical. In this connection, it was noted that $E$. coli K235 LPS induced marked responses in $\mathrm{C} 3 \mathrm{H} / \mathrm{HeN}$ spleen cell cultures but not in $\mathrm{C} 3 \mathrm{H} / \mathrm{HeJ}$ cell cultures.

In the LAL test, $B$. gingivalis strains possessed activities comparable to LPS of $E$. coli (Table 3). In the Shwartzman test, preparatory and provocative injection of $E$. coli K235 LPS induced a necrotic lesion at doses of more than $12.5 \mu \mathrm{g}$, and inflammatory lesions were observed at lower doses of LPS $(<0.785 \mu \mathrm{g})$. However, LPS from $B$. gingivalis exhibited no Shwartzman preparatory activity (Table 3 ).

\section{Antigenic properties of LPS from B. gingivalis}

A total of 10 hybridomas producing mAbs to LPS from $B$. gingivalis $381,6 / 26$ and HW24D-1 were obtained; the
Table 3. Chromogenic LAL test and local Shwartzman activity of LPS from $B$. gingivalis

\begin{tabular}{lcc}
\hline \hline & $\begin{array}{c}\text { LAL test } \\
\left(A_{405}\right)\end{array}$ & $\begin{array}{c}\text { Shwartzman reaction } \\
(\text { minimum dose, } \mu \mathrm{g})^{*}\end{array}$ \\
\hline E. coli & $1.530 \dagger$ & $12.5 \ddagger$ \\
B. gingivalis & 0.703 & $>200$ \\
381 & 0.779 & $>200$ \\
ATCC 33277 & 0.720 & $>200$ \\
BH18/10 & 0.913 & $>200$ \\
6/26 & 0.743 & $>200$ \\
OMZ314 & 0.601 & $>200$ \\
HW24D-1 & 0.685 & $>200$ \\
OMZ409 & \\
\hline \hline
\end{tabular}

* The minimum preparatory dose was determined as described in Methods; doses from 0.785-200 $\mu \mathrm{g}$ were tested.

$\dagger$ LPS from E. coli O111:B4.

$\ddagger$ LPS from $E$. coli K235.

cell lines were named 381-1, 381-2, 381-3, 6/26-1, 6/26-2, $6 / 26-3,6 / 26-4,6 / 26-5,6 / 26-6$ and $24 \mathrm{D} 1$, respectively. The isotypes of $\mathrm{mAbs} 381-1,381-2$ and 6/26-6, mAbs 6/26-1, 6/26-2, 6/26-3, 6/26-4 and 6/26-5, and $\mathrm{mAb} 24 \mathrm{D} 1$ were identified as IgG1, IgG3 and IgM, respectively. All mAbs were found to produce a $\kappa$ light chain. ELISA revealed that $\mathrm{mAb} 381-1$ reacted with only the LPS from strain 381, while mAb 381-2 reacted with that from 381 and ATCC 33277 (results not shown). The reaction patterns of mAbs 381-3, 6/26-2, 6/26-4 and 24D1 are shown in Fig. 3. The LPS from $B$. gingivalis strains 381 , ATCC 33277, BH18/10 and 6/26 reacted with both mAbs 381-3 and 6/26-2. mAb 6/26-4 reacted with LPS from all the strains of $B$. gingivalis tested. The $\mathrm{mAb} 6 / 26$ LPS series, except mAb 6/26-4, showed similar reaction patterns to 6/26-2 (results not shown). However, mAb 24D1 reacted only with the LPS from OMZ314, HW24D-1 and OMZ409. The response of OMZ314 LPS was strongest and that of OMZ409 was weakest. No 

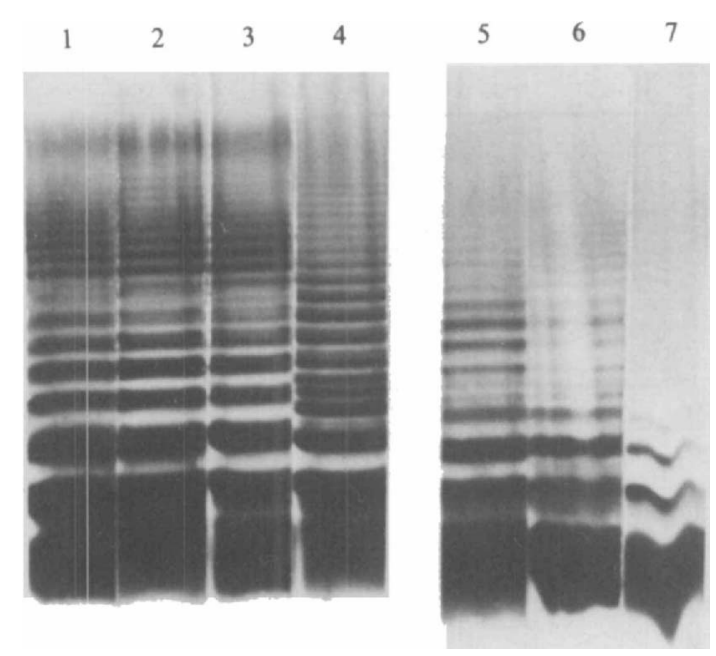

Fig. 1. Silver-stained gel after SDS-PAGE of LPS from seven strains of B. gingivalis. Electrophoresis was done in a $12.5 \%(\mathrm{w} / \mathrm{v})$ acrylamide gel, containing LPS from $B$. gingivalis strains 381 (lane 1), ATCC 33277 (lane 2), BH18/10 (lane 3), 6/26 (lane 4), OMZ314 (lane 5), HW24D-1 (lane 6) and OMZ409 (lane 7).

mAbs were found to react with LPS from strains of $B$. oralis, $B$. loescheii, $B$. intermedius and $B$. corporis.

Immunodiffusion patterns of the LPS preparations from $B$. gingivalis with the concentrated mAbs 381-3, 6/26-2 and 6/26-4 are shown in Fig. 4. The LPS from $B$. gingivalis strains 381 , ATCC $33277, \mathrm{BH} 18 / 10$ and $6 / 26$ formed a fused precipitin band with mAbs 381-3 and 6/26-2. mAb 6/26-4 formed a fused precipitin band with LPS from all the $B$. gingivalis strains. No precipitin band was observed with mAbs 381-1, 381-2, 6/26-6 and 24D1. $\mathrm{mAbs} 6 / 26-1,6 / 26-3$ and $6 / 26-5$ showed very similar immunodiffusion patterns to mAb 6/26-2 (results not shown).

\section{Discussion}

In previous studies it has been demonstrated that chemical and immunobiological properties of LPS from Bacteroides species were different from those of other oral periodontal pathogens such as Actinobacillus actinomycetemcomitans and species of Enterobacteriaceae (Koga et al., 1985, 1987; Hamada et al., 1988; Fujiwara et al., 1988). LPS from $B$. gingivalis has some chemical features in common with LPS of other oral and non-oral Bacteroides species (Nair et al., 1983; Weintraub et al., 1985).

The absence of KDO in LPS from Bacteroides species has been reported by several groups (Hofstad, 1974; Kasper et al., 1983; Johne \& Bryn, 1985). Our analyses of LPS from B. gingivalis (Koga et al., 1985) and other black-pigmented and related Bacteroides (unpublished
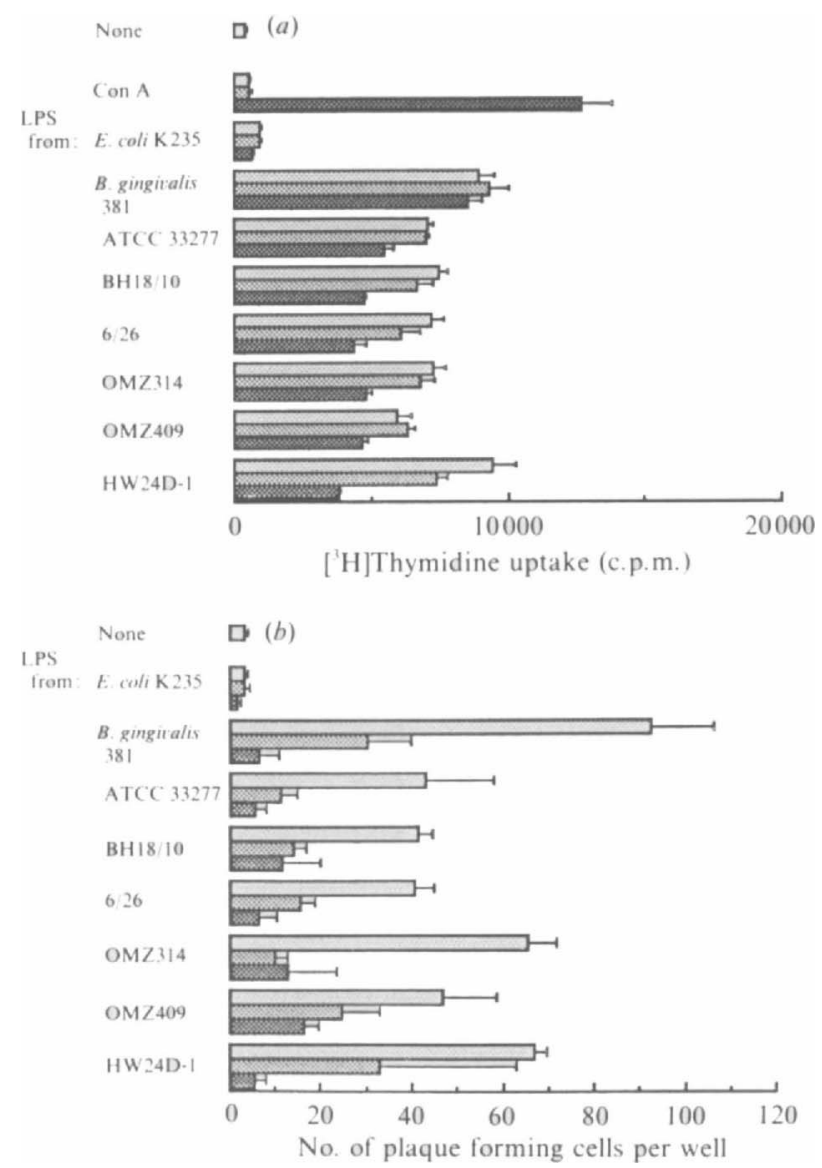

Fig. 2. Mitogenic responses (a) and polyclonal B cell activation responses $(b)$ of spleen cells from $\mathrm{C} 3 \mathrm{H} / \mathrm{HeJ}$ mice to LPS from $B$. gingivalis. For determination of mitogenic responses, spleen cells $(7 \times$ $10^{5}$ per well) from $\mathrm{C} 3 \mathrm{H} / \mathrm{HeN}$ and $\mathrm{C} 3 \mathrm{H} / \mathrm{HeJ}$ mice were incubated with $10 \mu \mathrm{g}(\square), 5 \mu \mathrm{g}$ (圈) and $1 \mu \mathrm{g}$ (閣) LPS or Con A per well or without LPS ( $\square$ ) in RPMI 1640 medium supplemented with $15 \mathrm{~mm}$-HEPES buffer (pH 7.2) at $37^{\circ} \mathrm{C}$ in a humidified atmosphere of $5 \%(\mathrm{v} / \mathrm{v}) \mathrm{CO}_{2}$ in air. Cultures were pulsed with $9.25 \mathrm{kBq}\left[{ }^{3} \mathrm{H}\right]$ thymidine during the last $6 \mathrm{~h}$ of a $48 \mathrm{~h}$ incubation period. For determination of polyclonal $\mathrm{B}$ cell activation responses, lymphoid cells were isolated from spleen cells of $\mathrm{C} 3 \mathrm{H} / \mathrm{HeN}$ and $\mathrm{C} 3 \mathrm{H} / \mathrm{HeJ}$ mice. The cells $\left(1 \times 10^{6}\right.$ per well $)$ were incubated with $10 \mu \mathrm{g}(\square), 1 \mu \mathrm{g}$ (圈) and $0.1 \mu \mathrm{g}$ ( LPS per well or without LPS ( $\square$ ) in RPMI 1640 medium supplemented with 2mercaptoethanol $(50 \mu \mathrm{M})$ and $10 \%(\mathrm{v} / \mathrm{v})$ foetal calf serum at $37^{\circ} \mathrm{C}$ in a humidified atmosphere of $5 \%(\mathrm{v} / \mathrm{v}) \mathrm{CO}_{2}$ in air. After $4 \mathrm{~d}$ incubation, anti-sheep erythrocyte plaque-forming cell responses were determined. Values are expressed as the mean \pm SD of three different cultures.

data) revealed only trace amounts of KDO by the thiobarbituric acid method of Karkhanis et al. (1978), and the colour developed was atypical. Therefore, we considered that the LPS of these Bacteroides contained no significant amounts of KDO. However, the study by Kumada et al. (1988) indicated that KDO became detectable by the thiobarbituric acid assay if LPS was pretreated with $3 \mathrm{M}-\mathrm{HCl}$ at $100^{\circ} \mathrm{C}$ for $30 \mathrm{~min}$. The authors concluded that Bacteroides LPS possess KDO that is substituted with phosphate in the 5-O-position of 
(a) $\mathrm{mAb} 381-3$

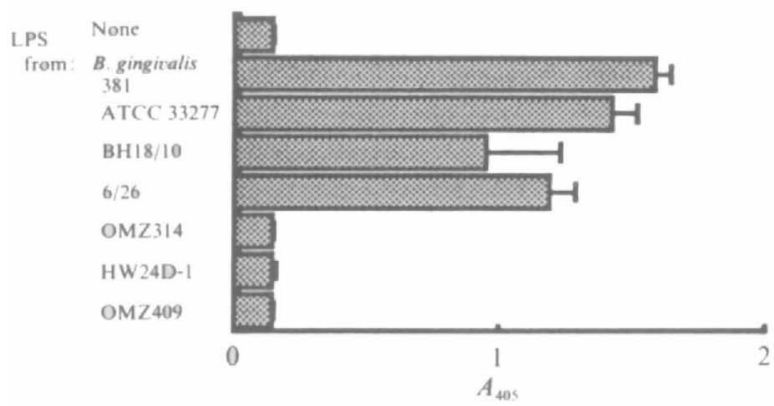

(c) $\mathrm{mAb} 6 / 26-4$

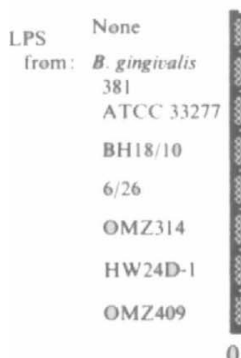

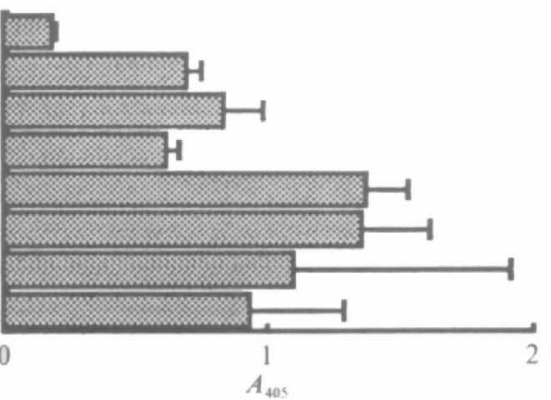

(b) $\mathrm{mAb} 6 / 26-2$
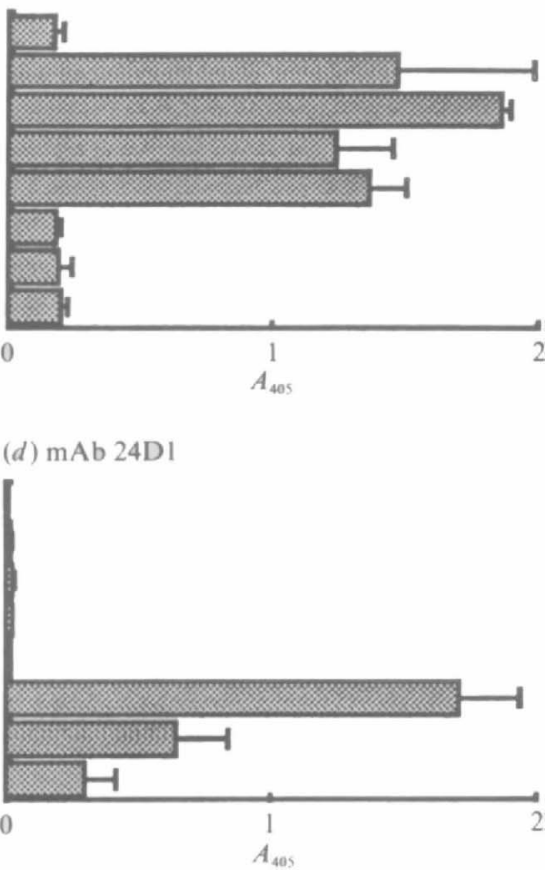

Fig. 3. ELISA of LPS from B. gingivalis strains 381, ATCC 33277, BH18/10, 6/26, OMZ314, HW24D-1 and OMZ409 with four mAbs raised against the LPS from $B$. gingivalis strains 381, 6/26 and HW24D-1. (a) mAb 381-3; (b) mAb 6/26-2; (c) mAb 6/26-4; (d) mAb 24D1. Undiluted culture supernatant of each hybridoma clone was used as $\mathrm{mAb}$.
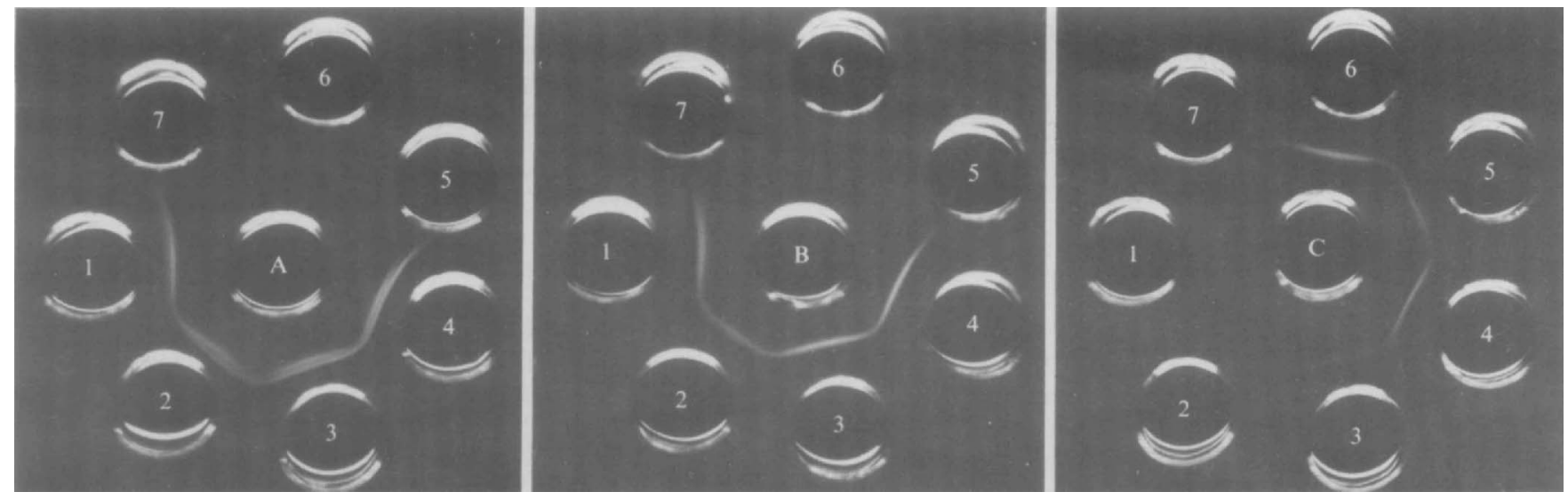

Fig. 4. Immunodiffusion pattern of LPS from $B$. gingivalis with $m A$ bs against LPS from $B$. gingivalis strains 381 (mAb 381-3, centre well $\mathrm{A})$, and 6/26 (mAb 6/26-2, centre well $\mathrm{B} ; \mathrm{mAb} 6 / 26-4$, centre well $\mathrm{C}$ ). The outer wells contained $10 \mu \mathrm{l}$ B. gingivalis LPS solutions (1 mg $\mathrm{ml}^{-1}$ ) from strains 381 (1), ATCC 33277 (2), BH18/10 (3), 6/26 (4), OMZ314 (5), HW24D-1 (6) and OMZ409 (7).

KDO. In this study, we followed their method and detected significant amounts of KDO. In this regard, Beckmann et al. (1989) noted that mild acid hydrolysis of the dephosphorylated LPS of $\boldsymbol{B}$. fragilis that had been treated with aqueous $50 \%$ hydrofluoric acid released KDO.
The fatty acid analyses revealed that 3-hydroxytetradecanoic acid (3-OH-C14:0), a major component of enterobacterial LPS, was not detected in LPS from any of the B. gingivalis strains (Table 2), nor in other Bacteroides species (Weintraub et al., 1985). The major fatty acids of LPS from $B$. gingivalis were branched 3-hydroxypenta- 
decanoic (branched 3-OH-C15:0) and branched 3hydroxyheptadecanoic (branched 3-OH-C17:0). The base peak and fragment ion peaks of their methyl esters in the mass spectrum were characteristic of 3-hydroxy fatty acid methyl esters (Ryhage \& Stenhagen, 1960). However, the branching site of these fatty acids is not yet known. As no fragment ion peaks specific for the branch were detected, it is suggested that the branching site is separate from the carboxyl radical. Wollenweber et al. (1980) detected 3-hydroxy-15-methyl-hexadecanoic acid (3-OH-iso-C17:0) in the LPS from B. fragilis and four other Bacteroides species, a report confirmed by other investigators (Kasper et al., 1983; Nair et al., 1983; Mashimo et al., 1985; Johne \& Bryn, 1986). We have found these branched 3-hydroxy fatty acids in the LPS from oral Bacteroides species such as $B$. oralis ATCC $33269, B$. loescheii ATCC 15930, B. intermedius ATCC 25611 and $B$. corporis ATCC 33457 (unpublished data). Thus, it appears that the presence of such fatty acids is a special feature of the LPS from Bacteroides species.

The LPS from all strains of $B$. gingivalis possessed mitogenic and polyclonal $B$ cell activation activities in spleen cell cultures from $\mathrm{C} 3 \mathrm{H} / \mathrm{HeN}$ mice as well as LPS nonresponder $\mathrm{C} 3 \mathrm{H} / \mathrm{HeJ}$ mice. This finding is an extension of the previous report indicating that the lipid portion isolated from $B$. gingivalis ATCC 33277 LPS by hydrolysis in $1 \mathrm{M}-\mathrm{HCl}$ at $100^{\circ} \mathrm{C}$ for $1 \mathrm{~h}$ was composed of fatty acids $(70.5 \%, w / w)$ and glucosamine $(22.5 \%$, w/w), and exhibited mitogenic activity against both $\mathrm{C} 3 \mathrm{H} / \mathrm{HeN}$ and $\mathrm{C} 3 \mathrm{H} / \mathrm{HeJ}$ mice (Fujiwara et al., 1988). Toxicities determined by the local Shwartzman reaction were very weak, supporting previous work (Sveen, 1977; Mansheim et al., 1978; Johne \& Bryn, 1986; Koga et al., 1987). However, activities in the chromogenic LAL assay were of the same order as LPS from $E$. coli. It has been reported that the biologically active entity of enterobacterial LPS is lipid A (Westphal et al., 1985). The fatty acid composition of LPS of $B$. gingivalis, with its branched 3-hydroxy fatty acids, differs from lipid A of $E$. coli, and may contribute to the difference in biological activities. Different chemical structures of the core region of LPS may also modulate the biological activities.

mAb 6/26-4 reacted with the LPS from all seven strains of $B$. gingivalis. Furthermore, immunodiffusion using rabbit polyclonal antisera raised against LPS from the seven test strains displayed a fused precipitin band with all $B$. gingivalis LPS examined. Neither mAbs nor rabbit antiserum raised against LPS from $B$. gingivalis reacted with LPS from other oral Bacteroides species. These results clearly indicated that there was a speciesspecific antigen in the LPS from $B$. gingivalis strains. Millar et al. (1987) reported that one mAb raised against
$B$. gingivalis 381 whole cells gave specific reactions against LPS from strain 381 and three other strains of $B$. gingivalis, but not against LPS from other Bacteroides species and species of Enterobacteriaceae. Using rabbit antisera to $B$. gingivalis whole cell serum, Okuda $e t$ al. (1986) found that LPS was one of the species-specific antigens among black-pigmented oral Bacteroides species. Using rabbit antiserum to Bacteroides LPS, we obtained similar results (Fujiwara et al., 1988).

The LPS from B. gingivalis strains 381, ATCC 33277 and $\mathrm{BH} 18 / 10$ formed a fused precipitin band with each other against rabbit anti-LPS serum and mAb 381-3. These results indicated that the antigenicity of the LPS from the three strains was very similar. Furthermore, the LPS from $B$. gingivalis $6 / 26$ reacted with $\mathrm{mAb} 381-3$, and the mAb 6/26 series, except 6/26-4, reacted with the LPS not only from strain $6 / 26$, but also with LPS from the three strains mentioned above. Conversely, mAb 24D1 reacted with the LPS from $B$. gingivalis strains OMZ314, HW24D-1 and OMZ409, but not with the LPS from $B$. gingivalis strains 381 and $6 / 26$. These results suggest that the $B$. gingivalis strains tested form at least two LPS serogroups, depending on their antigenic specificities as revealed by $\mathrm{mAbs}$ to $B$. gingivalis LPS. LPS serogroup I includes strains 381 , ATCC $33277, \mathrm{BH} 18 / 10$ and 6/26, while LPS serogroup II contains strains OMZ314, HW24D-1 and OMZ409. It should be noted here that the metabolic properties of $B$. gingivalis strains in terms of sugar fermentation and the production of phenylacetic acid were almost identical. In addition, the chemical and biological properties of the LPS from serogroups I and II were essentially similar.

Recently, we have found intra-species differences in the serological specificity of the fimbrial protein in $B$. gingivalis (unpublished). Some mAbs raised against chromatographically purified fimbriae from $B$. gingivalis 381 were found to react with the fimbriae from $B$. gingivalis strains 381, ATCC 33277 and BH18/10, but not with those from strains OMZ314, HW24D-1, OMZ409 and $6 / 26$. It is interesting that the serological heterogeneity of $B$. gingivalis LPS generally correlates with that of the fimbriae among the $B$. gingivalis strains, except for strain $6 / 26$. Although strain $6 / 26$ belongs to LPS serogroup $I$, the immunological specificity of the fimbriae of strain 6/26 is different from that of strain 381 . Also, the SDS-PAGE profile of LPS from B. gingivalis strains 381, ATCC 33277 and $B H 18 / 10$ is almost identical, but that of 6/26 LPS is somewhat different. Furthermore, an absorption experiment using rabbit polyclonal antibodies indicated that anti-381 LPS serum absorbed with strain 381 LPS reacted with neither 381 nor 6/26 LPS. Conversely, when anti-6/26 LPS serum was absorbed with $6 / 26$ LPS, its reactivity to strain $6 / 26$ LPS disappeared, while its reactivity to strain 381 LPS 
remained (data not shown). These results clearly suggest that strain 6/26 LPS has other antigenic determinant(s) which are lacking in strain 381 LPS.

This study was supported in part by grants-in-aid 01480430 and 01044085 for scientific research from the Ministry of Education, Science and Culture of Japan.

\section{References}

Beckmann, I., van EiJK, H. G., Meisel-Mikolajczyk, F. \& WALLENBURG, H. C. S. (1989). Detection of 2-keto-3-deoxyoctonate in endotoxins isolated from six reference strains of the Bacteroides fragilis group. International Journal of Biochemistry 21, 661-666.

BLIGH, E. G. \& DYER, W. J. (1959). A rapid method of total lipid extraction and purification. Canadian Journal of Biochemistry and Physiology 37, 911-917.

CunNingham, A. J. \& Szenberg, A. (1968). Further improvements in the plaque technique for detecting single antibody-forming cells. Immunology 14, 599-600.

Daly, C. G., Seymour, G. J. \& Kieser, J. B. (1980). Bacterial endotoxin: a role in chronic inflammatory periodontal disease? Journal of Oral Pathology 9, 1-15.

Fujwara, T., Nishihara, T., Koga, T. \& Hamada, S. (1988). Serological properties and immunobiological activities of lipopolysaccharides from black-pigmented and related oral Bacteroides species. Journal of General Microbiology 134, 2867-2876.

hamada, S., Koga, T., Nishihara, T., Fujiwara, T. \& Okahashi, N. (1988). Characterization and immunobiologic activities of lipopolysaccharides from periodontal bacteria. Advances in Dental Research 2, 284-291.

HOFSTAD, T. (1974). The distribution of heptose and 2-keto-3-deoxyoctonate in Bacteroidaceae. Journal of General Microbiology 85, 314 320.

JOHNE, B. \& BRYN, K. (1986). Chemical composition and biological properties of a lipopolysaccharide from Bacteroides intermedius. Acta Pathologica, Microbiologica et Immunologica Scandinavica B94, 265271.

Karkhanis, Y. D., Zeltner, J. Y., Jackson, J. J. \& Carlo, D. J. (1978). A new and improved microassay to determine 2-keto-3deoxyoctonate in lipopolysaccharide of Gram-negative bacteria. Analytical Biochemistry 85, 595-601.

Kasper, D. L., Weintraub, A., Lindberg, A. A. \& LönNGRen, J. (1983). Capsular polysaccharides and lipopolysaccharides from two Bacteroides fragilis reference strains: chemical and immunochemical characterization. Journal of Bacteriology 153, 991-997.

Koga, T., Nishihara, T., Fujiwara, T., Nisizawa, T., OKahashi, N., Noguchl, T. \& HaMada, S. (1985). Biochemical and immunobiological properties of lipopolysaccharide (LPS) from Bacteroides gingivalis and comparison with LPS from Escherichia coli. Infection and Immunity 47, 638-647.

Koga, T., Odaka, C., Moro, I., Fujiwara, T., Nishihara, T., OKAHASHI, N. \& HAMADA, S. (1987). Local Shwartzman activity of lipopolysaccharides from several selected strains of suspected periodontopathic bacteria. Journal of Periodontal Research 22, 103107.

Kumada, H., Watanabe, K., Umemoto, T., Haishima, Y., Kondo, S. \& HisATSUNE, K. (1988). Occurrence of $O$-phosphorylated 2-keto-3deoxyoctonate in the lipopolysaccharide of Bacteroides gingivalis. FEMS Microbiology Letters 51, 77-80.

Mansheim, B. J., ONDerdonk, A. B. \& Kasper, D. L. (1978). Immunochemical and biologic studies of the lipopolysaccharide of Bacteroides melaninogenicus subspecies asaccharolyticus. Journal of Immunology 120, 72-78.
Mashimo, J., Yoshida, M., Ikeuchi, K., Hata, S., Arata, S., Kasai, N., OKUDA, K. \& TAKazoe, I. (1985). Fatty acid composition and Shwartzman activity of lipopolysaccharides from oral bacteria. Microbiology and Immunology 29, 395-403.

MAYRAND, D. \& HolT, S. C. (1988). Biology of asaccharolytic blackpigmented Bacteroides species. Microbiological Reviews 52, 134-152.

Millar, S. J., Chen, P. B. \& Hausmann, E. (1987). Monoclonal antibody for identification of Bacteroides gingivalis lipopolysaccharide. Journal of Clinical Microbiology 25, 2437-2439.

Morrison, D. C. (1983). Bacterial endotoxins and pathogenesis. Reviews of Infectious Diseases 5, S733-S747.

Nair, B. C., MayberRy, W. R., Dziak, R., Chen, P. B., Levine, M. J. \& HaUSMANN, E. (1983). Biological effects of a purified lipopolysaccharide from Bacteroides gingivalis. Journal of Periodontal Research 18, 40-49.

Okuda, K., Ohta, K., Kato, T., Takazoe, I. \& Slots, J. (1986) Antigenic characteristics and serological identification of 10 blackpigmented Bacteroides species. Journal of Clinical Microbiology 24, 89-95.

R YHAGE, R. \& STENHAGEN, E. (1960). Mass spectrometric studies. VI. Methyl esters of normal chain oxo-, hydroxy-, methoxy- and epoxyacids. Arkiv för Kemi 15, 545-574.

SaWARdeker, J. S., Sloneker, J. H. \& Jeanes, A. (1965). Quantitative determination of monosaccharides as their alditol acetates by gas liquid chromatography. Analytical Chemistry 37, 1602-1604.

SCHENCK, K. \& MiCHAELSEN, T. E. (1987). IgG subclass distribution of serum antibodies against lipopolysaccharide from Bacteroides gingivalis in periodontal health and disease. Acta Pathologica, Microbiologica et Immunologica Scandinavica C95, 41-46.

Schenck, K., Helgeland, K. \& Tollefsen, T. (1987). Antibodies against lipopolysaccharide from Bacteroides gingivalis before and after periodontal treatment. Scandinavian Journal of Dental Research 95, 112-118.

SLOTs, J. \& GeNCo, R. J. (1984). Black-pigmented Bacteroides species, Capnocytophaga species, and Actinobacillus actinomycetemcomitans in human periodontal disease: virulence factors in colonization, survival, and tissue destruction. Journal of Dental Research 63, 412421.

Slots, J. \& Listgarten, M. A. (1988). Bacteroides gingivalis, Bacteroides intermedius and Actinobacillus actinomycetemcomitans in human periodontal diseases. Journal of Clinical Periodontology 15, 85-93.

SVEEN, K. (1977). The capacity of lipopolysaccharides from Bacteroides, Fusobacterium, and Veillonella to produce skin inflammation and the local and generalized Shwartzman reaction in rabbits. Journal of Periodontal Research 12, 340-350.

Trevelyan, W. E. \& Harrison, J. S. (1956). Studies on yeast metabolism. 7. Yeast carbohydrate fractions, separation from nucleic acid, analysis, and behaviour during anaerobic fermentation. Biochemical Journal 63, 23-33.

TsaI, C. M. \& Frasch, C. E. (1982). A sensitive silver stain for detecting lipopolysaccharides in polyacrylamide gels. Analytical Biochemistry 119, 115-119.

Weintraub, A., Larsson, B. E. \& Lindberg, A. A. (1985). Chemical and immunochemical analyses of Bacteroides fragilis lipopolysaccharides. Infection and Immunity 49, 197-201.

WestPhAL, O. \& JANN, K. (1965). Bacterial lipopolysaccharides. Extraction with phenol-water and further applications of the procedure. Methods in Carbohydrate Chemistry 5, 83-91.

WestPhal, O., LüDeritz, O., Galanos, C., Mayer, H. \& Rietschel, E. T. (1985). The story of bacterial endotoxin. In Advances in Immunopharmacology pp. 13-34. Edited by L. Chedid, J. W. Hadden, F. Spreafico, P. Dukor \& D. Willoughby. Oxford: Pergamon Press. Wollenweber, H. W., Rietschel, E. T., Hofstad, T., Weintraub, A. \& LiNDBERG, A. A. (1980). Nature, type of linkage, quantity, and absolute configuration of (3-hydroxy) fatty acids in lipopolysaccharides from Bacteroides fragilis NCTC 9343 and related strains. Journal of Bacteriology 144, 898-903. 